\title{
Mental health services in Nepal: Is it too late?
}

Mental health has historically been neglected both in the developed and developing world. It was not included in the Millennium Development Goals, the global targets for the developing world's fight towards better health and development [1]. However, over the past couple of years, it is increasingly recognised as an important public health concern and calls have been made for its inclusion in the post-2015 sustainable development goals [2]. The 66th World Health Assembly, consisting of M inisters of Health of 194 M ember States including Nepal, adopted the WHO's Comprehensive Mental Health Action Plan 2013-2020 in M ay 2013 [3]. Policies surrounding healthcare have often focused on the physical wellbeing of people without considering their psychological health. This is despite studies showing that mental health problems account for $14 \%$ of the global burden of disease [4]. Though this is a global phenomenon there are disparities between Nepal's provision of medical resources towards this area of healthcare.

In Nepal "mental health receives insignificant attention" at all levels of society5 from the government to the general public. This is reflected in the limited provision of resources towards mental healthcare. Although there are no accurate data on the prevalence of mental disorders in Nepal, a study has indicated to the prevalence to be as high as $37.5 \%$ in rural communities [6]. The government spend less than $1 \%$ of its total healthcare budget in this area [5]. M ore than $80 \%$ of psychiatric inpatient beds in the country are in Kathmandu, including the one psychiatric hospital, and all the outpatient units are in major urban centres [7]. Clearly the majority rural population has extremely restricted access to specialist mental health facilities. There is only one specialised hospital 8,9,10 despite the high rates of mental health disorders such as depression and anxiety.

There is still no National M ental Health programme or a division of mental health in the M inistry of Health \& Population to implement the 2006 national health policy [12]. The Government of Nepal has attempted to include mental health services as a basic primary health care component, however it still remains inaccessible to most of the population at the primary care level.120nly $2 \%$ of medical and nursing training is dedicated to mental health, and most qualified doctors and nurses work in the cities [7]. The only programmes implemented at primary care level are community mental health interventions provided by Non-Governmental Organisation, Centre for M ental Health \& Counselling (CM C) in 17 of the 75 districts in the country [12].

Nepal also has several "risk factors" which often contribute towards mental health problems, such as poverty, lack of education, discrimination and trauma.13 These problems have been further attributed Nepal's complex history of civil unrest, and social inequality [14-16]

There is a lot of stigma associated with mental illness among general population and health professionals in Nepal [17]. They found that one third of nurses felt unable to work with mentally ill people and whom they thought were 'violent and dangerous.' Also 10\% of pharmacy students felt that depression was a valid reason for rejection from pharmacy school [18]. One third of non-psychiatrist hospital consultants said psychiatric treatment
Simkhada P*, van Teijlingen $\mathrm{E}^{* *}$ Marahatta SB*** *Professor of International Public Health, Centre for Public Health, Liverpool John M oores University UK, *Visiting Professor, Manmohan M emorial Institute of Health Sciences (M M IHS), *Visiting Professor, Nobel College, Pokhara University, Nepal.

**Professor, CM M PH, Bournemouth University, UK Bournemouth House *** Department of Community M edicine, M anmohan M emorial M edical College, Nepal 


\section{Editorial}

was of little benefit to people with mental disorders. M ost had no experience of mental health; those who did, had significantly more positive attitudes [19].

In Nepal it is women of a reproductive age that suffer the highest rates of suicide and mental health problems [20-22]. The number of suicides within this group has increased from 22 per 100,000 in 1998 to 28 per 100,000 in 2008 [23]. Suicide is now one of the leading causes of death for women of a reproductive age [23, 24].

There is need to prioritize mental-health-issues and services in Nepal. The Journal of Manmohan M emorial Institute of Health Sciences (JM M IHS) is supporting this call for more emphasis of mental-health issues. Thus in this issue, we have included a review paper exploring the issues around suicide among women in Nepal. Our key message is that there is far too little emphasis on mental health, but it is not toolate!

\section{References}

\section{References}

1.WHO. M ental Health Global Action Programme 2002. (Online). Available at http://www.who.int/mental health/media/en/265.pdf (Accessed Oct. 2014)

2.Tomlinson, M. Global M ental Health: A sustainable post developmental Goal? International Health ;2013:5 1-3

3.WHO . M ental Health Action Plan 2013-2020.[cited 2014 Oct].Available http://apps.who.int/iris/bitstream/10665/89966/1/9789241506021_eng.pdf

4.Prince, M, Patel, V., Saxena, S., M aj, M., M aselko, J., Phillips, M. "No health without mental health." Lancet 370,2007; 859-877.

5.Regmi, S., Pokharei, A., Ojha, S., Pradhan, S. and Chapagain, G. "Nepal mental health country profile." International Review of Psychiatry,2004. 16 (12): 142-149.

6.Khattri, J.B., Poudel, B.M., Thapa, P., Godar, S.T., Tirkey, S., Ramesh, K. and Chakrabortty, P.K. (. An Epidemiological Study of Psychiatric Cases in a Rural Community of Nepal. Nepal Journal of Medical Science,2013; 2(1): 52-56.

7.Upadhyaya K.D., Chandra, V. and Saxena, S. WHO-AIM S Report on M ental Health System Nepal, Kathmandu, WHO \& M inistry of Health Nepal,2006.

8.Tol, W.A., Kohrt, B.A., Jordans, M.J.D., Thapa, S.B., Pettigrew, J., Upadhaya, N. de Jong, J.T.V.M. . Political violence and mental health: A multi-disciplinary review of the literature in Nepal. Social Science \& M edicine,2010; 70(1): 35-44.

9.Upadhyaya, K. "Policy, strategy and plan of action to improve the mental health service in Nepal." Journal of Gandaki M edical College ,2009;2 (4): 1-4.

10.Jha, A. and Adhikari, S. "M ental health services in new Nepal- Observations, objections and outlooks for the future." Journal of Nepal M edical Association, 2009; 48 (174), 185-190.

11.World Health Organization. WHO-AIM S report on mental health system in Nepal,2006. [online].[cited 2014 Oct]. Available:URL: http://www.who.int/mental_health/evidence/nepal_who_aims_report.pdf

12.Jha, A., Ranjan, S., Pradhan, P.K. and Jha, T. Challenges of setting up psychiatric services in Nepal: Lessons from the first year of Janakpur Project. Asian Journal of Psychiatry,2011; 4(4): 297-299.

13.Kohrt, B., Hruschka, D.J., Worthman, C.M., Kunz, R.D., Baldwin, J.L., Upadhaya, N., Acharya, N.R., Koirala, S, Thapa, S.B., Tol, W.A., Jordans, M .J., Robkin, N., Sharma, V.D. and Nepal, M.K. Political violence \& mental health in Nepal: prospective study. British Journal Psychiatry,2012; 201(4):268-275.

14.Kohrt, B. and Harper, I. "Navigating diagnoses: Understanding mind-body relations, mental health and stigma in Nepal." Culture, M edicine \& Psychiatry, 2008; 32: 462-491.

15.Gautam, R., Saito, T. and Kai, I. "Leisure and religious activity participation and mental health: gender analysis of older adults in Nepal." BM C Public Health,2007; 7, 299-309.

16.Tsutsumi, A. Izutsu, T., Poudyal, A., Kato, S. and M arui, E. "M ental health of female survivors of human trafficking in Nepal." Social Science \& Medicine,2008.66, 1841-1847.

17.Shyangwa, P., Singh, S. and*, Khandelwal S. Knowledge and attitude about mental illness among nursing staff. Journal of the Nepal Medical Association.2003; 42: 27-31.

18.WHO Suicide Prevention 2010.[Online].[Cited 2014 Oct]. Available from:URL:http://www.who.int/mental health/media/en/265.pdf.

19.Subedi, S, Aich, T., Shah, S. and Thapa, D. Non-psychiatry consultant's attitude towards psychiatry: a study from Universal College of M edical Sciences, Nepal. Journal of Universal College of M edical Sciences.2014; 1 (4): 2-6.

20.Joshi, S. and Kharel, J. Violence against women in Nepal: An overview.2008. The Free Library [online] http://www.thefreelibrary.com/Violence Against Women in Nepal -- An Overview- a01073875052 [01/09/2014].

21.Hicks, M. and Bhugra, D. "Perceived causes of suicide attempts by U.K. South Asian women." American Journal of Orthopsychiatry.2003. 73 (4), 455462.

22.Subba, S.H., Binu, V.S., M enezes, R.G., Kanchan, T., Arun, M., Patil, R., Pant, S., Saha, A., De, A. and Rana M.S. "Pattern and trend of deliberate selfharm in Western Nepal." Journal of Forensic Science .2009.54 (3): 704-707.

23. Pradhan, A., Poudel, P., Thomas, D. and Barnett, S. "A review of the evidence: suicide among women in Nepal." A report by the National Health Sector Support Program, DFID. Kathmandu.2011.

24.Ho-Yen, S., Bondevik, G., Eberhard-Gran, M. and Bjorvatn, B. "Factors associated with depressive symptoms among postnatal women in Nepal." Acta Obstetricia et Gynecologica.2007. 86, 291-297. 